Military Technical College Kobry El-Kobbah, Cairo, Egypt

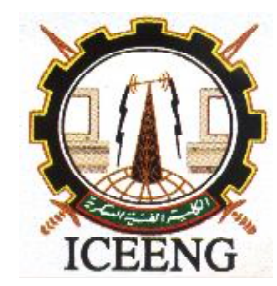

$9^{\text {th }}$ International Conference on Electrical Engineering ICEENG 2014

\title{
Octagonal Monopole Antenna with Band-Notched characteristics for UWB applications
}

\author{
By \\ Ahmed A.Ibrahim \\ Hesham F.A.Hamed \\ Sama Ahmed \\ Mai Hany \\ Rania Emad
}

\section{$\underline{\text { Abstract: }}$}

Octagonal shape monopole antenna with dual band notched features which is used for ultra wide band applications is presented. The monopole antenna has good impedance matching from $3.4 \mathrm{GHz}$ to $12 \mathrm{GHz}$. The dual bands notched are achieved by using Ushaped parasitic strip and meandered slot etched in the radiating patch. The first band notched is achieved using meandered slot to reduce the interference with WIMAX from $3.3 \mathrm{GHz}$ to $3.9 \mathrm{GHz}$. The second band notched is achieved using $\mathrm{U}$-shaped parasitic strip which is placed above the ground plane to eliminate the interference with WLAN from $5.2 \mathrm{GHz}$ to $5.9 \mathrm{GHz}$. The proposed antenna has VSWR $<2$ except the notched bands. The simulated results confirm that the proposed antenna is suitable for UWB applications.

\section{Keywords:}

UWB antenna, dual band frequency notches, U-shaped parasitic strip, meandered slot

* Egyptian Armed Forces 


\section{Introduction:}

The Federal Communications Commission (FCC) is approved rules for the commercial operation of ultra wide band (UWB) within the range of $3.1 \mathrm{GHz}$ to $10.6 \mathrm{GHz}$ [1] .So, the design and implementation of UWB systems have been attracted much attention for communication systems. The UWB communication systems have several advantages such as enabling high data rates, increased communication security, low power consumption and simple hardware configuration in practical applications [2]. The UWB antenna has to achieve many requirements such as small size, omnidirectional radiation patterns, high and stable gain across the whole band and they can be made compatible with the RF components [3-8]. The Wireless LAN applications (5 GHz $-6 \mathrm{GHz})$ and WiMAX applications $(3.3 \mathrm{GHz}-3.9 \mathrm{GHz})$ technologies are occupying small portions of the UWB band, which introduce interference between them. In order to eliminate this interference, the antenna is designed to have band-notched features. Researchers have proposed several techniques to design the band notched antenna [9-14].

In this paper, UWB antenna with dual notched characteristics is presented. First, a UWB antenna is designed, which exhibits radiating characteristics in the frequency band 3.3 $\mathrm{GHz}-12 \mathrm{GHz}$. Second, U-shaped parasitic strip and meandered slot are used to achieve the band-notched characteristics. The first notch is achieved at frequency band (3.3 $\mathrm{GHz}-4.1 \mathrm{GHz})$. The second notch is achieved at frequency band $(5.1 \mathrm{GHz}-6 \mathrm{GHz})$. The detail design of the antenna is introduced. The commercial software CST microwave studio was employed in the full wave simulations.

\section{UWB Antenna Configuration:}

The configuration of the UWB octagonal monopole antenna is illustrated in Fig.1. The radiating element is designed in the form of octagonal shape and the antenna is fed using 50 microstrip line. The octagonal monopole antenna is chosen due to it has wide band characteristics and it has good radiation features. The octagonal monopole antenna is printed on substrate FR4 with relative permittivity $(\varepsilon r)=4.4$, and thickness $(\mathrm{h})$ $=1.6 \mathrm{~mm}$. From Fig.1 (b) the partial ground plan is used to enhance the matched impedance of the UWB antenna from $3.3 \mathrm{GHz}$ to $12 \mathrm{GHz}$. The simulated results of return loss and VSWR of the UWB antenna are shown in Fig.2. From the simulated result the antenna has good impedance matching and VSWR lower than 2 from $3.3 \mathrm{GHz}$ up to $12 \mathrm{GHz}$. 


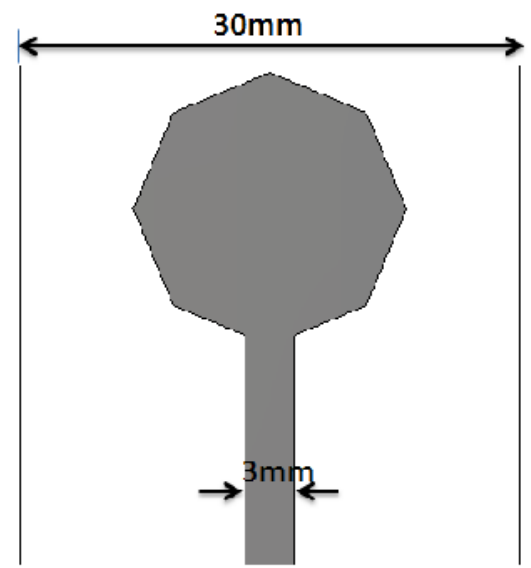

(a)

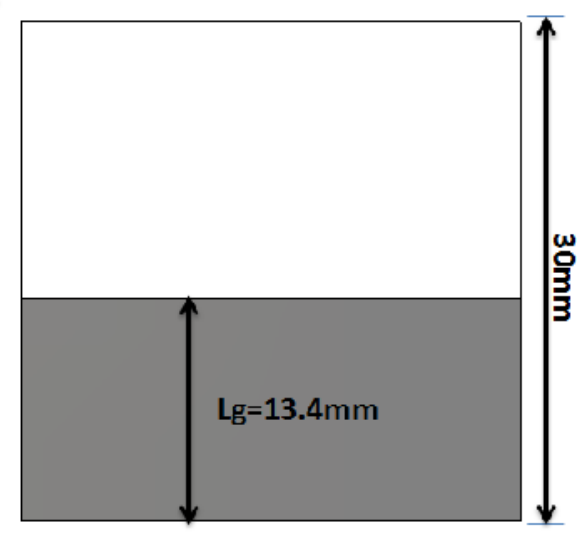

(b)

Figure(1):.2-D layout of the octoganal monopole antenna (a)Top veiw (b) back veiw

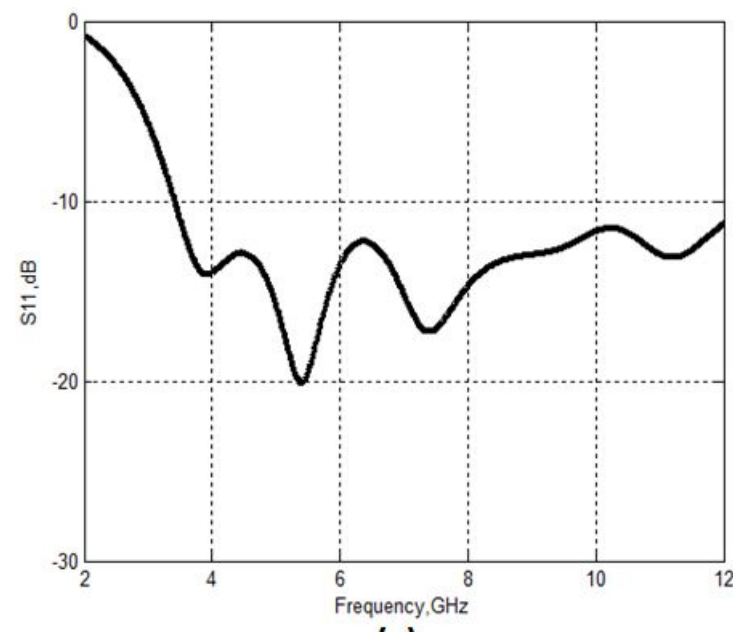

(a)

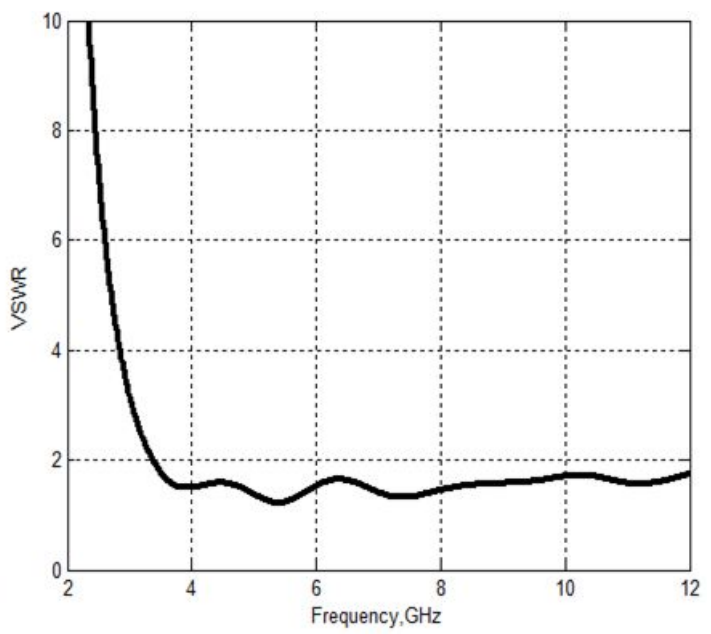

(b)

Figure(2): Simulated results of UWB antenna response (a) Return Loss (b)VSWR

\section{Proposed Antenna with Dual Band-Notched Features:}

The 2-D layout of the proposed UWB antenna is illustrated in Fig.3. To achieve the desired frequency band notch from $3.3 \mathrm{GHz}$ - $3.9 \mathrm{GHz}$ (WIMAX applications), meandered slot which equals to quarter wavelength of the notched frequency is etched in radiating patch as illustrated in Fig.3 (a). Also in order to rejecting frequency band of WLAN from $5.2 \mathrm{GHz}$ - $5.9 \mathrm{GHz}$ ), The U-shape parasitic strip which equals half wavelength of the notched frequency is employee above the ground plane as demonstrated in Fig.3 (b). This frequency band notched is designed to reduce the interference between the WIMAX, WLAN applications and the UWB operations. The 
simulated results of return loss and VSWR are shown in Fig.4 (a) and Fig.4 (b) respectively. It is obvious that there are two notches at the desired frequency band. From the simulated results the return loss and VSWR of the proposed antenna lower than 2 from $3 \mathrm{GHz}$ to $10.8 \mathrm{GHz}$ except the band notched region from $3.3 \mathrm{GHz}$ to $4.1 \mathrm{GHz}$ and from $5.1 \mathrm{GHz}$ to $6 \mathrm{GHz}$.

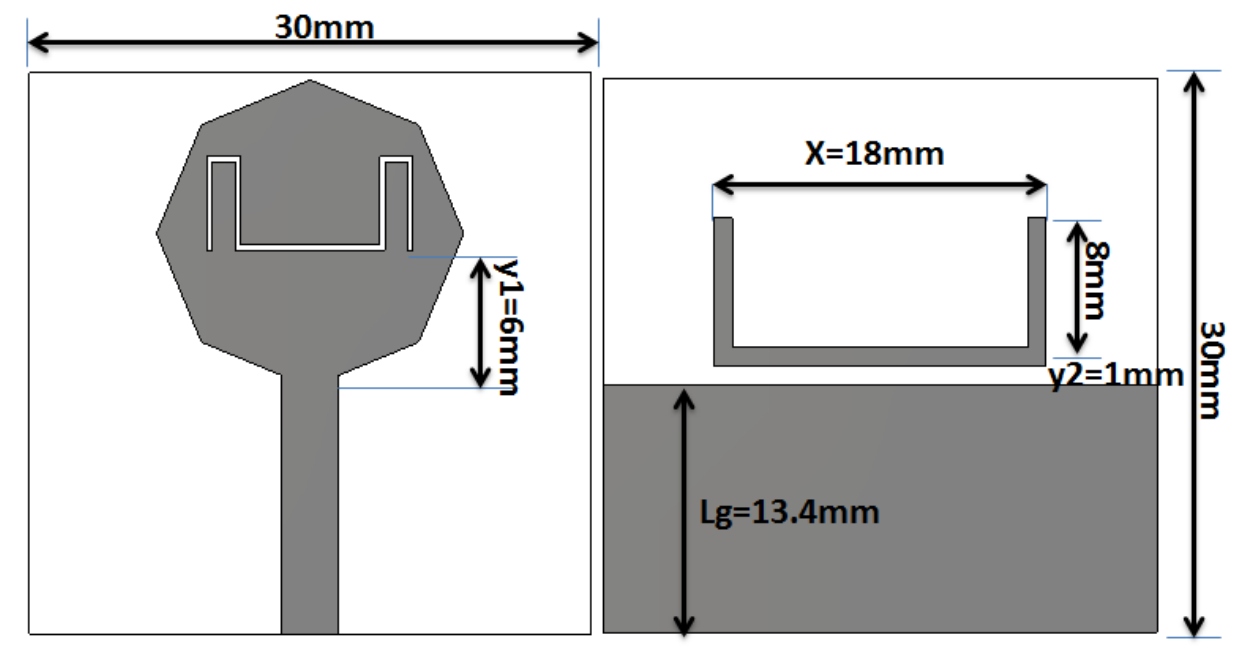

Figure(3): 2-D layout of the proposed UWB antenna (a)Top veiw (b) back veiw

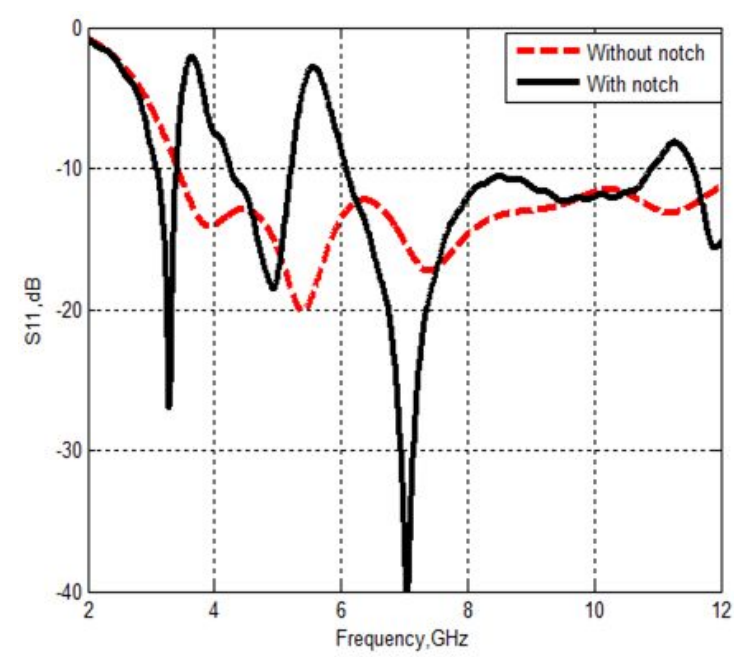

(a)

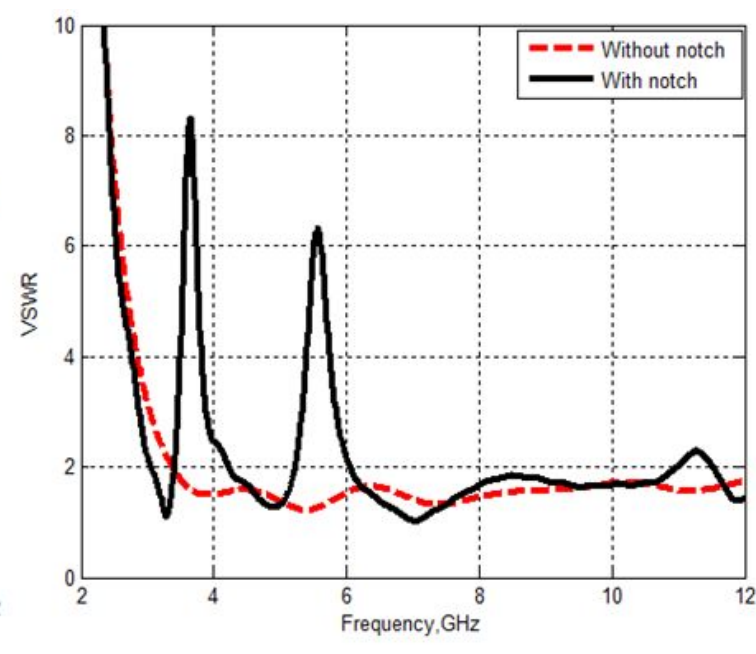

(b)

Figure(4):: Simulated results of proposed UWB antenna response (a) Return Loss (b)VSWR 


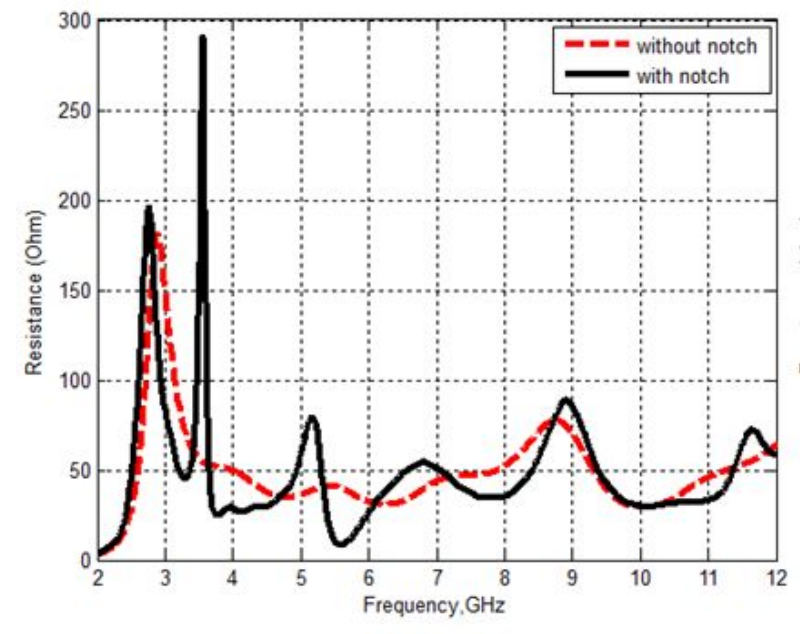

(a)

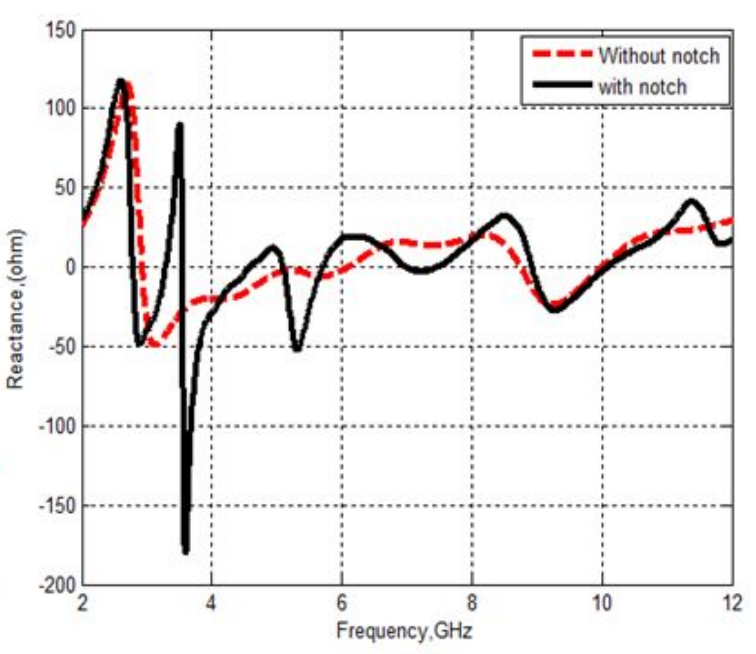

(b)

Figure(5): The Simulated input impeadeance of the UWB antenna (a) Resistance (b) Reactance

The real (resistive) and imaginary (reactive) components of the antenna's input impedance are are illustrated in Fig.5 (a) and Fig.5 (b) respectively. From Fig.5(a) and Fig.5(b) it is seen that from the dashed red curve (without notch) the resistive component fluctuate around $50 \mathrm{ohms}$ and the reactive component fluctuate around 0 ohm. Also from From Fig.5(a) and Fig.5(b) it is clear that from the solid black curve (withnotch) the resistive component jumps to $300 \mathrm{ohms}$ and the reactive component becomes - $150 \mathrm{ohms}$ from $3.3 \mathrm{GHz}$ to $4.1 \mathrm{GHz}$ the first notch and the resistance jumb again to $80 \mathrm{ohm}$ and the reactance to $-50 \mathrm{ohm}$ from $5 \mathrm{GHz}$ to $6 \mathrm{GHz}$ the second notch. In this case the matching is destroyed and a high value of return loss will appear.

\section{Parametric Analysis:}

The important criteria in the design of the desired UWB antenna are adjusting the impedance bandwidth and the desired center frequency of the notched band. In the previous section, dual band notched is designed by using meandered slot and U-shape parasitic strip to provide notched band at center frequency of $3.5 \mathrm{GHz}$ for WIMAX applications and $5.5 \mathrm{GHz}$ for WLAN applications. There are several parameters affect the behavior of the proposed antenna and some of them have strong affect than others. Therefore, in this parametric study the parameter which has significant effect on the antenna performance such as the position of the slot distance higher than feed line with distance (y1), the distance of U-shaped above ground plane with distance (y2), the length of the ground length $(\mathrm{Lg})$ and the length of the U-shape parasitic strip (x) is investigated. First, The effect of the ground plane length $(\mathrm{Lg})$ on the proposed antenna performance when $\mathrm{y} 1=6 \mathrm{~mm}, \mathrm{y} 2=1 \mathrm{~mm}$ and $\mathrm{x}=18 \mathrm{~mm}$ is illustrated in Fig.6 (a). It is 
obvious that, the length of $\mathrm{Lg}$ has strong effect on the antenna bandwidth. Also the notched band affected by the length of the Lg. The optimized length of the $\mathrm{Lg}=13.4$ $\mathrm{mm}$. Second, the effect of the meandered slot position (y1) is shown in Fig.6 (b). It is clear that, the bandwidth of the notch is decreased with increasing in the position (y1) and the optimized position is chosen to be $6 \mathrm{~mm}$ when the $\mathrm{y} 2=1 \mathrm{~mm}$ and the $\mathrm{Lg}=13.4$ $\mathrm{mm}$ and $\mathrm{x}=18 \mathrm{~mm}$. Third, the effect of the position of the U-shape parasitic strip (y2) above the ground plane on the antenna return loss is studied as shown in Fig.7 (a). From Fig.7 (a) it is obvious that, when the distance (y1) is increased above the ground plane the effect of the U-shaped strip on the return loss wasn't appear .Therefore, the optimized place to the U-shaped strip was $1 \mathrm{~mm}$ above the ground plan to achieve the required notched frequency band. Finally, the effect of the length of the U-shape parasitic strip (x) is demonstrated in Fig.7 (b) .The length of the U-shape parasitic strip acts as the inductance. Therefore, when the length of the resonator increases the resonance frequency of the notch decreases. The resonance frequency is decreased from $6.7 \mathrm{GHz}$ to $5.5 \mathrm{GHz}$ when the length of the $\mathrm{U}$ - shape is increased from $10 \mathrm{~mm}$ to $18 \mathrm{~mm}$.

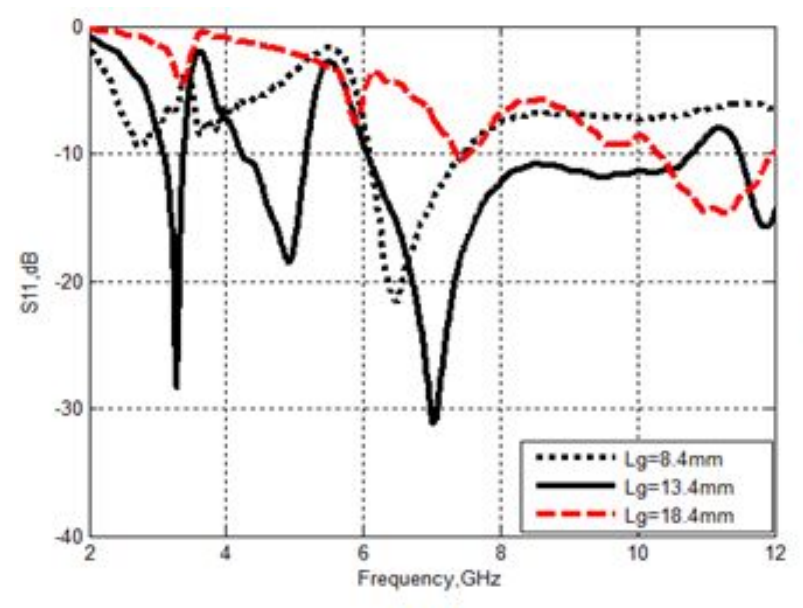

(a)

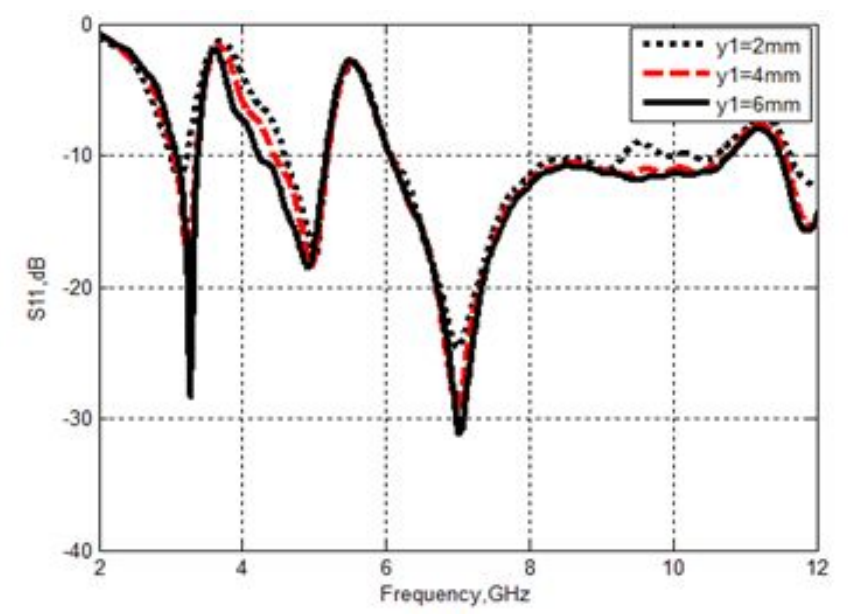

(b)

Figure(6): Simulated return loss of UWB antenna (a) at different ground legnth( $L g)$ (b)at diffrend slot position (yl) 


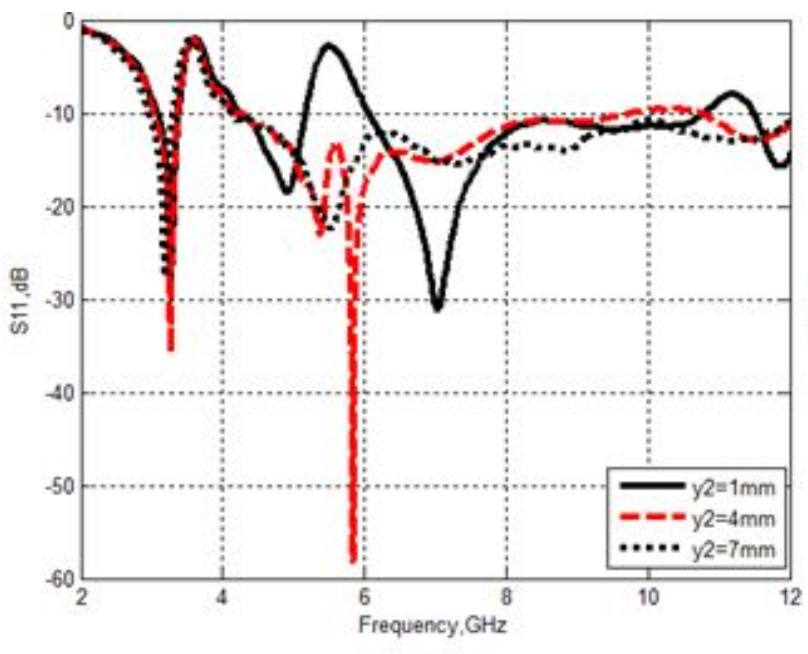

(a)

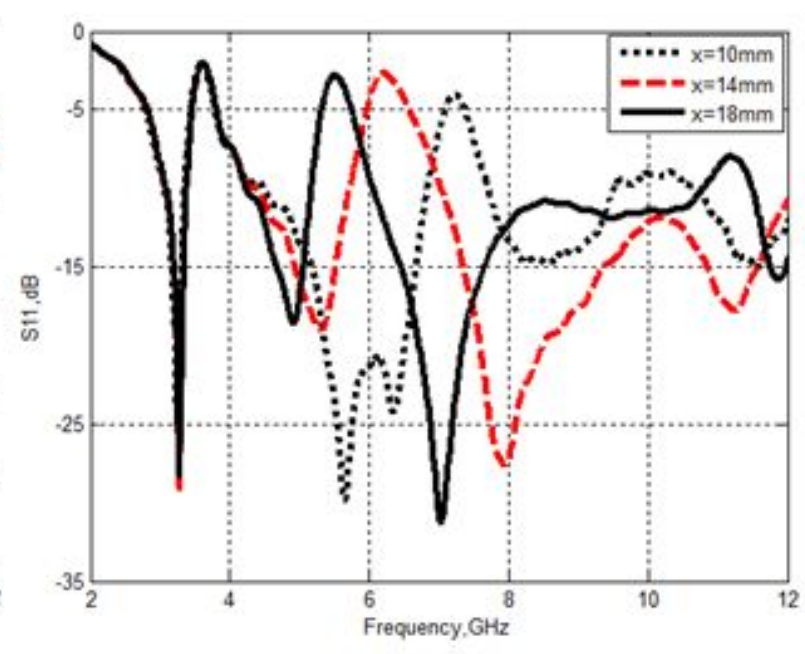

(b)

Figure(7): Simulated return loss of UWB antenna (a) at different $U$-shape position (y2) (b) at diffrend $U$-shape legnth $(x)$

\section{Current Distributions and Radiation Pattern:}

In order to understand the behavior of the band-notched characteristics, the simulated current distributions of the proposed antenna at $3.5 \mathrm{GHz}$ and $5.5 \mathrm{GHz}$ are investigated as shown in Fig8. First, from Fig.8 (a) the current at frequency $3.5 \mathrm{GHz}$ which is considered the center of the band notched of the WIMAX applications is concentrated around the meandered slot. Also from Fig.8 (b) it is obvious that the surface current is concentrated around the U-shape parasitic strip at $5.5 \mathrm{GHz}$ which is the center of the WLAN frequency band. From two figures it is concluded that the antenna didn't radiate at these frequency bands.

The simulated radiation patterns for the $\mathrm{x}-\mathrm{z}, \mathrm{y}-\mathrm{z}$ and $\mathrm{x}-\mathrm{y}$ planes of the proposed antenna at $7 \mathrm{GHz}$ and $9.5 \mathrm{GHz}$ are shown in Fig. 9 and Fig.10 respectively. It is clear that, the antenna has nearly Omni-directional patterns in $x-y$ and $y-z$ planes and a bi-directional in the $\mathrm{x}-\mathrm{z}$ plane.

A comparison between the simulated peak gain and efficiency of the proposed antenna with and without notch is illustrated in Fig.11 (a), and Fig.11 (a) (b), respectively. As shown in the figure, it is clear that in case of the absence of the notch the average gain equals $3 \mathrm{~dB}$, approximately, and the averaged efficiency equals $85 \%$. On the other hand the average peak gain and efficiency equals $3 \mathrm{~dB}$ and $80 \%$ except the two notched frequency band the peak gain and efficiency equal $-3 \mathrm{~dB},-2 \mathrm{~dB}$ and $-12 \%,-10 \%$, respectively in the case of the presence of the notch. 

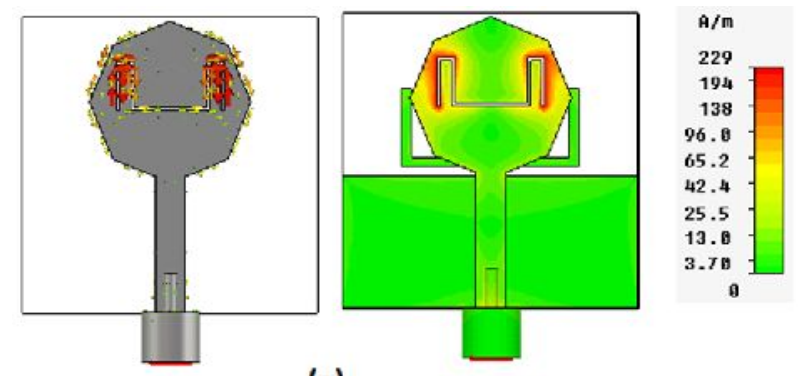

(a)
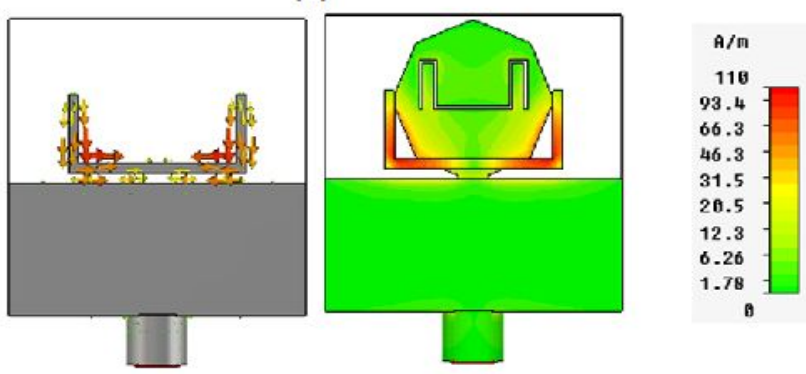

(b)

Figure(8): Simulated surface current distributions of proposed $U W B($ a) at $f=3.5 \mathrm{GHz}$ (b) at $f=5.5 \mathrm{GHz}$

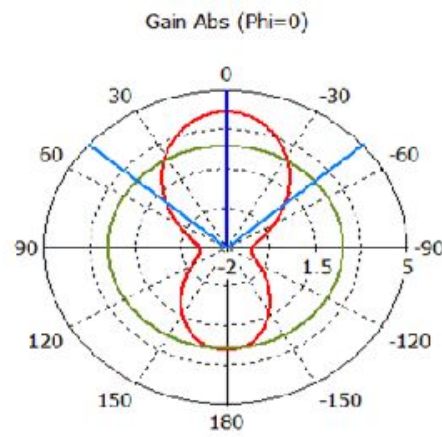

Theta / Degree vs. dB Gain Abs (Phi=90)

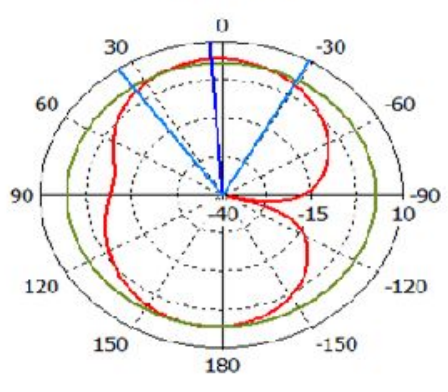

Theta / Degree vs. cB y-Z Plane

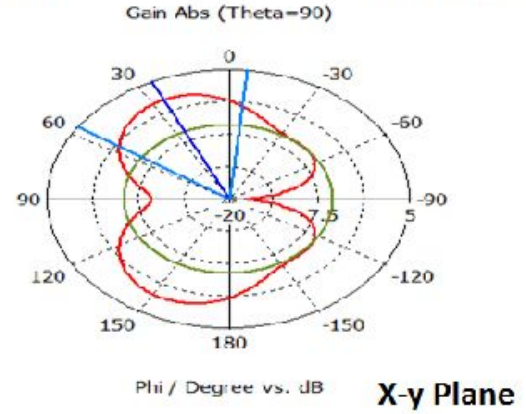

Figure(9): The simulated gain of the proposed antenna at $7 \mathrm{GHz}$ 


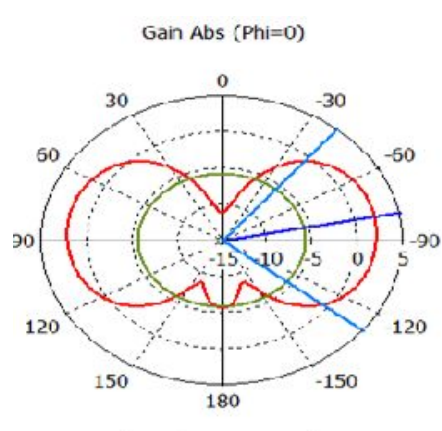

Theta / Degree vs. dB X-Z Plane

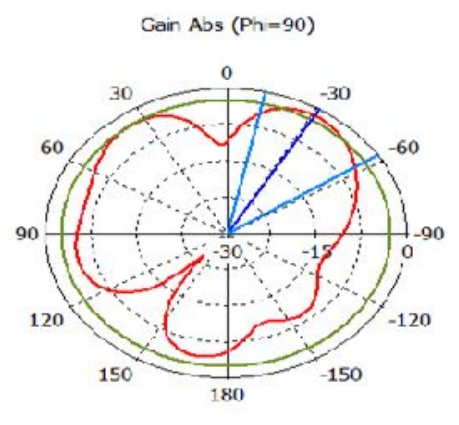

Iheta / Degree vs. dB

y-Z Plane

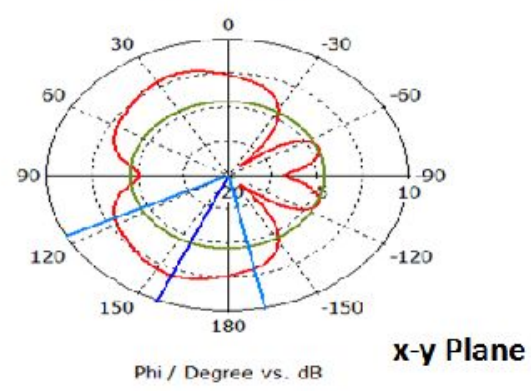

Figure(10): The simulated gain of the proposed antenna at $9.5 \mathrm{GHz}$

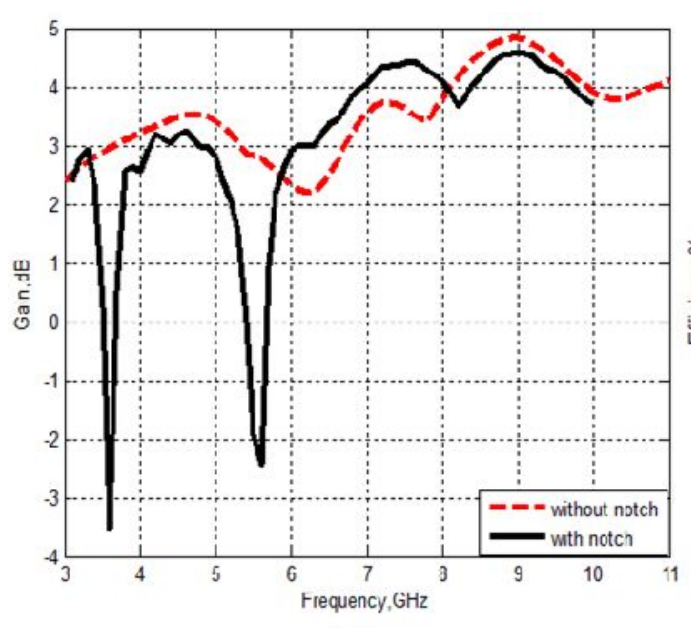

(a)

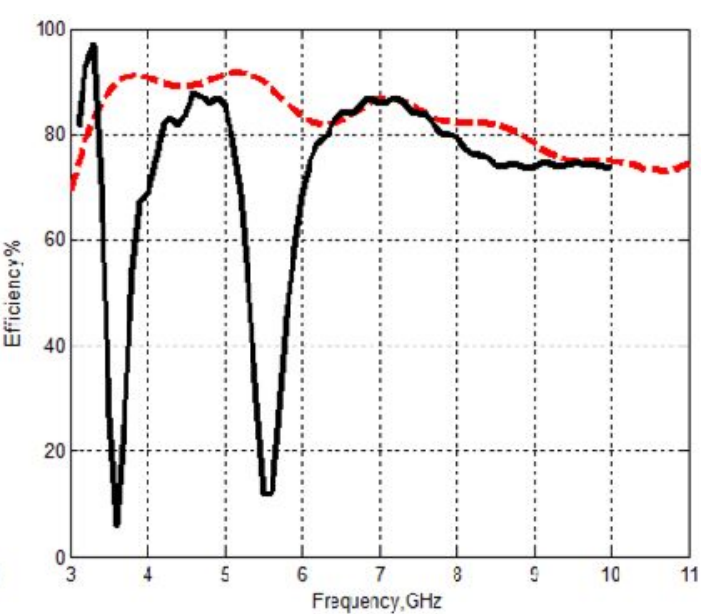

(b)

Figure(11): (a) Simulated peak gain of the UWB antenna (b) Simulated efficiencyof the $U W B$ antenna

\section{Conclusions:}

Monopole antenna with octagonal shape radiator has been introduced. The proposed antenna has been used for ultra wide band applications with dual band notched 
characteristics. The dual bands notched have been achieved by employing U-shaped parasitic strip and meandered slot etched in the octagonal radiating patch. The interference with WIMAX applications from $3.3 \mathrm{GHz}$ to $3.9 \mathrm{GHz}$ and WLAN applications from $5.2 \mathrm{GHz}$ to $5.9 \mathrm{GHz}$ has been reduced by using meandered slot and Ushaped parasitic strip respectively. The simulated results confirm that the proposed antenna is suitable for UWB applications.

\section{References:}

[1] First Report and order, "Revision of part 15 of the commission's Rule Regarding Ultra-Wideband Transmission System FCC 02-48," Federal Communications Commission, 2002.

[2] Fontana, R. J., "Recent system applications of short-pulse ultra-wideband (UWB) technology," IEEE Trans. MTT, Vol. 52, No. 9, 2087-2104, 2004.

[3] Taheri, M. M. S., H. R. Hassani, and S. M. A. Nezhad, "UWB printed slot antenna with Bluetooth and dual notch bands," IEEE Antennas Wireless Propag. Lett., Vol. 10, 255-258, 2011.

[4] Kumar R. and P. Malathi, "On the design of CPW-feed diamond shape fractal antenna for UWB applications," International Journal of Electronics, Vol. 98, 1157-1168, 2011.

[5] Osman, M. A. R., M. K. A. Rahim, M. Azfar, N. A. Samsuri, F. Zubir, and K. Kamardin, "Design, implementation and performance of ultra-wideband textile antenna," Progress In Electromagnetics Research B, Vol. 27, 307-325, 2011.

[6] Zhan, K., Q. Guo, and K. Huang, "A miniature planar antenna for Bluetooth and UWB applications," Journal of Electromagnetic Waves and Applications, Vol. 24, No. 16, 2299-2308, 2010.

[7] Azim, R., M. T. Islam, and N. Misran, "Ground modified double- sided printed compact UWB antenna," IET Electronics Letters, Vol. 47, No. 1, 9-11, 2011.

[8] Li WT, Hei YQ, Feng W, Shi XW. "Planar antenna for 3G/Bluetooth/WiMAX and UWB applications with dual band-notched characteristics". IEEE Antennas Wireless Propag. Lett. 2012; 11:61-64.

[9] Lin CC, Huang CY. "Band-notched ultra-wideband slot antenna with a pair of ARC-shaped metallic arms". J. Electromagn. Waves Appl. 2011, Vol. 25,889899.

[10] Yang G, Chu Q-X, Tu Z-H. "A Compact band-notched UWB antenna with controllable notched bandwidths by using coupled slots". J. Electromagn. Waves Appl. 2011, Vol. 25,2148-2157

[11] Liao X-J, Yang H-C, Li Y. "Aperture UWB antenna with triple band-notched characteristics". Electron Lett. 2011, Vol. 44, 77-79.

[12] Ahmed A.Ibrahim, Hesham F. A. Hamed, Mohammed Alla El-Din,Azhar Abdel- 
alla,Eman Yahia "A compact Planer UWB Antenna with Band-Notched Characteristics", ICET 2014, accepted,

[13] Thomas, K. G. and M. Sreenivasan, "A simple ultrawideband planar rectangular printed antenna with band dispensation," IEEE Transactions on Antennas and Propagation, Vol. 58, No. 1, 27-34, 2010.

[14] A. M. Abbosh, M. E. Bialkowski, "Design of UWB planar band-notched antenna using parasitic elements," IEEE Trans. Antenna Propag., vol. 57, no. 3, pp. 796-799, March 2009. 